\title{
Protocol for assessing access to commercial property (particularly offices and shops) for people with disabilities
}

Received (in revised form): 19 October 2007

\section{Jack Rostron}

is a solicitor, chartered surveyor, chartered town planner and construction management tutor at Liverpool John Moore's University. He researches the needs of the physically disabled in the built environment. He is the author of several papers and books and sometime adviser to the World Health Organization.

\begin{abstract}
This paper attempts to achieve two aims. First, to provide design guidance to professional advisers, occupiers, owners and developers of commercial property (especially offices and shops) to meet the needs of people with disabilities. Secondly, to provide a systematic and measured means of evaluating an existing building. Since the passage of the Disability Discrimination Act 1995, owners and occupiers have to meet increasingly stringent requirements to remove barriers to access for the physically disabled. It is hoped that this paper will go some way towards achieving this goal.
\end{abstract}

\section{Keywords:}

physical disability, access, design, assessment, buildings

Journal of Retail and Leisure Property (2008) 7, 103-118. doi:10.1057/rlp.2008.3; published online 5 March 2008

\section{INTRODUCTION}

Access to commercial property, especially offices and shops, for physically disabled people should afford the same standard of comfort, choice and independence as it does for the able bodied. Ideally, disabled people should be able to enter and work in any office and shop in any retail outlet.

Perhaps more importantly the Disability Discrimination Act, 1995 introduced wide ranging laws requiring those offering services and goods

Jack Rostron

Liverpool John Moore's University Peter Jost Centre

Byrom Street

Liverpool L3 3AF, UK

Tel: +44 (o) 1512312856

Fax: +44 (0) 1512312815

E-mail: j.rostron@ljmu.ac.uk for the public to implement measures providing access for the disabled The Disability Discrimination (Providers of Services) (Adjustment to Premises) Regulations 2001. Since 1 October 2004 service providers have to make 'reasonable adjustments' to any physical barriers that may prevent people with disabilities using services Disability Discrimination Act, 1995.

Before any meaningful discussion can be undertaken concerning making access for physically disabled people, some definitions may prove 
useful. Under the Disability Discrimination Act, 1995, disability is defined as...' a physical or mental impairment, which has a substantial and long term adverse effect on a person's ability to carry out normal day to day activities'.

Under the implementation phases of the Disability Discrimination Act 1995 via the Code of Practice 2002, since 1 October 2004 where physical features make it unreasonably difficult for people with disabilities to access services offered to the public, the providers of such services have to; remove the feature, alter it so that it no longer has the effect, or provide a reasonable alternative method of making the service available to disabled people.

The Disability Rights Commission, 2005 defines physical features as... 'anything on the premises arising from a buildings design or construction or the approach to, exit from or access to such a building, feature, fittings, furniture, equipment or materials and any other physical element or quality of land in the premises... whether temporary or permanent'.

This protocol is designed to identify potential barriers and offers guidance in making acceptable changes.

Recent advances in technology for the physically disabled have created many new opportunities for people with disabilities to work and to purchase goods and services provided they are afforded physical access to the office or retail environment.

As there are many design guides available for new buildings such as the Centre for Accessible Environments (2004a, b), Palfreyman, 1993 and Royal National Institute for the Blind (2004), this paper is concerned only with converting and refurbishing existing ones.

\section{PURPOSE OF PAPER}

The first part of this paper provides design guidance for professional advisers, occupiers, owners and developers of offices and shops to meet the needs of physically disabled customers and employees for which existing property is suitable while the Appendix provides a means to determine whether an existing building is suitable to meet the needs of the physically disabled.

\section{Interior}

\section{Entrance}

A level unobstructed entrance area on both sides of the door makes access easier. Floor surfaces both sides of the door should be made of slipresistant material.

The possibility for more generous use of space should be used in the planning of entrance doors, which should have a clear opening of at least $810 \mathrm{~mm}$.

Other entrances provided for visitors, staff, etc, should also be accessible to people with disabilities.

A ramp with a gradient no greater than 1:12 may be needed to gain entry depending on the characteristics of the site and building. 
Thresholds should be level and never greater than $15 \mathrm{~mm}$ high.

A threshold that is too high for a wheelchair to negotiate can be adapted either by using bevelled strips or removing the threshold.

An automatic door-opening device is the most appropriate form of entry for the physically disabled. An electric remote door opener combined with an intercom system is the most desirable arrangement.

Automatic sliding doors with a contact mat designed to accept unevenly distributed pressure are the most appropriate form of entry, facilitating both wheelchairs and people using crutches.

If automatic opening doors are not suitable, a single leaf side-hung door with an easily operated action opening with minimum force is the most suitable.

The doorway should be wide enough (minimum $810 \mathrm{~mm}$ ) to allow sufficient space for a wheelchair user to pass through.

Disabled people cannot react quickly to possible collisions and where privacy is not important a vision panel $900-1,500 \mathrm{~mm}$ from floor level should be incorporated to allow people approaching to be seen.

The door handle should be easily reached by a wheelchair user and positioned 760-914 $\mathrm{mm}$ from the floor level. The handle and locks should be easily operated by one hand, while affording proper security.

A space provided alongside the leading edge of a door reduces the risk of a wheelchair user being prevented from reaching the door handle as a result of the wheelchair footrest colliding with the flanking wall.

The door closer should allow sufficient time to allow slow or frail persons to pass and the door should not need much effort to open and close.

Kicking plates should be provided wherever possible to protect the door from damage caused by wheelchairs.

Signs should be clear and suitably placed to show directions to water closets (WCs), lifts, stairs, etc.

\section{RECEPTION/FOYER}

Entrance lobbies with two sets of doors create additional hindrance to the physically disabled and should be avoided if at all possible.

If entrance lobbies are essential, they should allow a wheelchair user to move clear of one door before using the next. Space should also be made available for someone assisting a disabled person or passing in the opposite direction. Transitional lighting should be provided to reduce contrast between the building interior and exterior.

Where doors are fully glazed, an applied hazard cue should be incorporated to accommodate persons with impaired vision. The hazard cue may incorporate a company logo.

Revolving doors are commonly installed in shops because they afford effective thermal insulation but they cannot be used by wheelchair-bound people. An auxiliary side-hung door with a clear opening of at least $810 \mathrm{~mm}$ should be incorporated by any set of revolving doors. It should be clearly signed and should not include high-pressure spring door closers.

Some larger types of revolving door may be acceptable, especially at supermarkets, providing they are large enough to accommodate several 
people, are fitted with stop mechanisms, which operate as soon as resistance is felt and rotate slowly.

Double swing doors should be avoided wherever possible, but where installed should have kicking plates on both surfaces and glazed with toughened or wired glass.

Solid doors should incorporate an appropriate vision panel 900$1,500 \mathrm{~mm}$ from ground level.

The use of a hot air curtain at the entrance door has advantages for the physically disabled, avoiding the need for a second set of doors, thereby enabling greater ease of use. They can, however, be expensive to install, run and maintain.

Signposting to important points in the building should be provided. The display of sign plates advertising facilities available for the disabled is advocated. The international symbol of accessibility should always be used on sign plates and should particularly identify usable vertical circulation facilities, usable cloakroom facilities and public telephones.

\section{Sales floors}

\section{Layout}

The general layout of sales areas should facilitate safety, comfort and convenience for disabled people.

Ideally all sales floor space should be accessible by wheelchair and all display surfaces, storage facilities and equipment within reach of someone in a wheelchair.

Visual aids such as contrasting colours at changes of floor level will assist partially sighted people.

\section{Equipment (especially for employees)}

While the universal accessibility of the physically disabled is the desired aim, it is perhaps not possible to accommodate the full range of disabilities in one system specification.

Cabinets should be fitted with drawer handles suitable for persons with low muscle power in fingers and hands. The most appropriate are those flattened in the horizontal plane, which allow fingers to curl around. This type of handle is also easier to operate by able-bodied people.

At least some of the 'workstations' should have variable height worktops to accommodate different types of wheelchair height.

With regard to cash registers, computers, etc, the keyboard, VDU and CPU should have facilities to accommodate usage by a range of physical disabilities. Types of adaptations range from raised keyboard 'templates' to facilitate persons with poor finger control, to suck/blow control switches for paralysed employees. In order to accommodate correctly the particular requirements of an individual physically disabled person, the type of equipment installed should be designed and procured to meet the particular circumstances.

An induction loop and/or other audio equipment should be installed where persons with impaired hearing work.

In meeting rooms for a person with hearing impairment they need to receive a signal about $20 \mathrm{~dB}$ above that received by a person with "normal 
hearing'. Usually either an induction loop or infrared system is used. The induction loop depends on a signal from a microphone passing to an amplifier directing a current around a loop in the relevant space. The listener's hearing aid picks up the sound via the magnetic field generated. Infrared systems radiate light received by a personal receiver converting it to sound.

British Telecom provides a wide and attractive range of telephone handsets to meet a variety of disabilities and should be consulted when designing for individual needs.

Radiators should be recessed; the valves operated easily and exposed sharp edges avoided.

Other forms of heating and air conditioning systems can create background noise, which can be annoying and distracting for people with hearing difficulties. They should be chosen and regularly maintained with a view to minimising noise.

Power supply cables should be routed away from seating positions as they can generate a considerable magnetic field, which can cause discomfort to people using hearing aids.

Lighting systems should be designed to be easily controllable and meet the needs of individuals.

Lighting fixtures should be located where they do not cause glare, disorienting shadows and unpleasant reflections.

Desks should be positioned away from bright spots, which result in the users face being in shadow, making lip reading difficult.

Uplighting produces a glare-free and comfortable type of illumination. Fluorescent down lighting often creates glare, which is uncomfortable to visually impaired people, and a magnetic field, which inconveniences people using hearing aids.

Lighting systems should be designed to highlight colours and enhance textures, creating visual cues for visually impaired people.

\section{Cafeterias and self-service dining areas}

\section{Cafeterias}

Cafeterias and dining areas should allow full access for disabled people. In the case of large cafeterias at least certain dining areas should be accessible by wheelchair users.

In buildings where there are a number of dining areas each should allow for wheelchair access.

Where there are a number of dining tables set aside for use by wheelchair users, they must be usable without the need to transfer out of the wheelchair.

Circulation spaces should not be blocked by customers seated in wheelchairs.

The counters should be at a level $835-950 \mathrm{~mm}$ to allow use by ambulant and wheelchair-bound customers.

High tables may be preferred by some wheelchair users but may prove inconvenient to ambulant users. A minimum floor to under-table height of $750 \mathrm{~mm}$ is required to accommodate wheelchair armrests. In most situations they are not recommended. 


\section{Self-service dining areas}

Criteria for good dining area layouts are the same for both able bodied and disabled users. Additional points especially applicable to disabled users are as follows:

1. Space between fittings should be a minimum of $1,400 \mathrm{~mm}$ to allow room for wheelchair turning.

2. Windows should be easily accessible for cleaning, opening and operating curtains.

3. There should be an unbroken level work surface between the cooking hobs and the sink so that pans of boiling water can be slid from one to the other.

4. Cooking hobs and oven should be separate units. The oven unit should be mounted so that the middle shelf is in level with the adjacent worktop.

5. Work surfaces with knee access under should be provided in as many places as possible especially at the sink. Insulation should be provided to protect knees from the possibility of being burnt by hot pipes.

6. Wall storage units should be accessible by a person seated in a wheelchair and should not be carried into corners over ' $\mathrm{L}$ '-shaped worktops.

\section{Toilet/washroom}

Sanitary conveniences provided for use by disabled visitors and customers may consist of unisex compartments.

For staff, the requirements will be satisfied if WC provision for disabled people is 'integral' within the traditional separate facilities for men and women, or is 'unisex'.

The requirements are met if the provision for wheelchair users of both sexes is on alternate floors, provided that the cumulative horizontal travel distances from a work station to the $\mathrm{WC}$ is no more than $40 \mathrm{~m}$ and, in a building provided with lift access, the general provision for sanitary conveniences is in areas to which anyone using the building has unrestricted access.

In a building, which has stair access only, suitable sanitary accommodation for wheelchair users should be provided in the principal entrance storey unless that storey contains only the principal entrance and vertical circulation areas.

If a building contains more than one WC compartment for wheelchair users, the opportunity should be taken of providing both left-hand and right-hand transfer layouts.

\section{WC's}

In all cases space for oblique or lateral transfer to the WC from a wheelchair must be provided.

A WC with a high-level cistern may in some cases be preferable to a low-level cistern because it enables grab rails to be fixed to the rear wall if necessary. 
The height of the WC bowl should be about $450 \mathrm{~mm}$ for wheelchair users to aid transfer. This gives a seat height of approximately $475 \mathrm{~mm}$. For ambulant disabled people a bowl rim height of $430 \mathrm{~mm}$ is recommended.

WC compartments should contain a hand rinse basin that should be fixed at a rim height of $900 \mathrm{~mm}$ for ambulant disabled people and $750 \mathrm{~mm}$ for chair-bound people.

Basins with integral horizontal surfaces for placing items such as; make-up, etc should be specified. Washbasins inset into a horizontal plastic laminate covered surface are particularly recommended.

As some disabled people will use a basin for support it must be adequately supported. Support brackets should be built into the wall rather than screw fixed. Leg supports are suitable for ambulant disabled, but would restrict wheelchair approach.

A mirror should be fixed over the washbasin extending as low as possible so that it is usable by wheelchair bound people.

Floor coverings should be waterproof, water resistant and slip resistant. Sheet vinyl makes an excellent covering.

Grab rails should be coated in plastic to afford a firm grip.

\section{Circulation}

\section{Horizontal circulation}

Corridors should be at least $1,200 \mathrm{~mm}$ wide. For corridors accessed by a stairway the unobstructed width should be $1,000 \mathrm{~mm}$.

A level surface for the full extent of the floor is essential. Where there is a step down then ideally the floor level should be raised to the general level provided there is sufficient headroom.

A cheaper and less disruptive method, which is suitable for smaller buildings, is the installation of a step lift. These are usually hydraulically or pneumatically operated and sometimes require the provision of a pit up to $300 \mathrm{~mm}$ deep. Step lifts are particularly useful where installation of a ramp would have detrimental planning implications. They should be designed in accordance with BS 64401983 'Code of Practice for Powered lifting platform for use by disabled people'. The lift must be large enough to accommodate at least one wheelchair user together with a companion.

Doors must have a minimum clear opening of $810 \mathrm{~mm}$.

The space into which the door opens should be unobstructed on the side next to the leading edge for at least $300 \mathrm{~mm}$, unless the door can be opened by an automatic control, or is in a situation where it may be reasonable to anticipate assistance.

Side-hung doors, where latched, should be fitted with lever furniture mounted $1,040 \mathrm{~mm}$ from the floor. For wheelchair users, an auxiliary pull handle may be fitted to the trailing face of the door to enable the door to be closed as the person passes through.

Where possible and appropriate doors should be omitted altogether. Where it is intended to omit doors special consideration should be paid to heating and ventilating to avoid draughts and means of escape requirements. 
Each door across an accessible corridor or passageway should be provided with a vision panel at least $900-1,500 \mathrm{~mm}$ high.

Doors where possible should contrast in colour to the surrounding walls to assist those with impaired sight.

Sliding doors are sometimes used to save floor space. Their installation, however, is not generally recommended for disabled people for the following reasons:

1. Wheelchair users find it difficult to pull with sufficient force in the plane of the door. Consequently the sliding gear tends to wear out rapidly and there is a real risk of the door coming off the track.

2. Sliding doors with good quality gear are more expensive than sidehung doors especially where an existing side-hung door is converted.

3. Locking devices for sliding doors are more difficult to operate.

4. Bottom guides or tracks interfere with carpet laying.

The trailing face of a side-hung door should be protected to a height of $400 \mathrm{~mm}$. Where existing doors are panelled the bottom rail only should be protected. Suitable material for protection includes fabric backed vinyl sheet or plastic laminate. Both types can be fixed with contact adhesive.

Side-hung doors should be solid core to facilitate fixing of auxiliary handles and to resist impact damage inflicted by wheelchair footrests.

Doors to WC's and washrooms should be openable from the outside in an emergency.

Along long routes seats, with a range of seating heights, should be provided at intervals or where waits are likely.

In seating areas a 'parking bay' for wheelchair users should be provided adjacent to the seats.

\section{Vertical circulation}

The best means of circulation for disabled people is a passenger lift. Such installations, however, are expensive proposals, especially for smaller offices.

Powered lifts are best for large changes in level.

An automatic lift door-reopening device should be fitted.

Lift controls should be accessible from a wheelchair.

Raised symbols on lift controls will be useful for the blind. Braille is not appropriate as not many blind people can read it.

An alarm should be fitted in the lift.

Internal stairs should be designed to the following standards:

1. The rise of any flight between landings should be less than $1,200 \mathrm{~mm}$.

2. Tread goings should be of uniform width throughout the staircase and not less than $250 \mathrm{~mm}$.

3. The rise should be uniform throughout the staircase and not exceed $170 \mathrm{~mm}$. Open tread risers should be avoided. Splayed risers should be used instead of risers with nosings.

4. Staircases of two or more steps require a continuous handrail on both sides. 
5. There should be an unobstructed width between handrails of at least $1,000 \mathrm{~mm}$.

6. All staircases and surrounding areas should be well lit.

7. Contrasting colour strips should clearly mark tread edges to help people with visual disabilities.

An interior ramp with a slope no steeper than 1:12 may be appropriate where level changes are minor and for wheelchair users or other persons with limited disabilities.

The dimensions for internal ramps are essentially the same as for external ramps.

Handrails should always be provided and designed to the following standards:

1. They should have a cross-section of not more than $52 \mathrm{~mm}$.

2. The handrail should provide a clearance of at least $45 \mathrm{~mm}$ from the wall and allow a complete unobstructed grip.

3. The handrail should be at least $900 \mathrm{~mm}$ above the pitch line of a flight.

The provision of refuges for disabled people while awaiting evacuation by the fire service is dealt with in British Standard 5588. During an evacuation, disabled people and wheelchair users especially should be able to await evacuation in safe refuges on protected staircases, corridors and lobbies.

\section{Electrical fittings}

Light switches should be located at the same height as the door handle adjacent to the opening side of the door.

Rocker switches are recommended for general use. Switches where the whole plate operates as a rocker are particularly recommended.

All socket outlets should be switched and shuttered. Ordinary twin socket outlets with switches placed together in the centre of the unit are difficult to manipulate when both plugs are in position. Fittings with the switches between the sockets and the perimeter of the unit or other types tested in use by disabled people should be specified.

Socket outlets likely to be used by disabled employees should be positioned at a height of $1,040 \mathrm{~mm}$ to align with light switches and doorknobs. Where this height is considered unacceptable for aesthetic reasons or to avoid trailing flexes, they should be placed at a minimum height of $500 \mathrm{~mm}$ from the floor.

\section{Heating}

Many disabled people undertake mainly sedentary activities; therefore, a higher air temperature is required to maintain a normal level of comfort.

The installation should be able to maintain work areas at $22^{\circ} \mathrm{C}$ and other areas at $17^{\circ} \mathrm{C}$.

The heat emitting appliances chosen should have controls, which are accessible without bending, and should be designed for use by people with impaired grip. Recessed controls should be avoided. 
Controls should not be lower than $700 \mathrm{~mm}$ or higher than $1,100 \mathrm{~mm}$ from the floor.

Radiator valves should be within reach and easily operated by the disabled.

Where wheelchair-manoeuvring space is critical, for example in corridors, radiators should be raised to $250 \mathrm{~mm}$ from the floor to clear feet and wheelchair footrests.

\section{Signs}

The design of signage should be consistent both inside and outside of the building.

Particular attention should be given to legibility and careful detailing. The size, style, colour and background should provide a clear simple message.

Raised lettering at hand reach height will be of assistance to blind people. Single letters, numerals and symbols should be used and located at standard positions throughout the building.

Braille symbols are not recommended as only a very small proportion of visually impaired people can read it and it may distract attention from normal signage.

Symbols should be as pictorial as possible.

The normal convention for signage is white out of a dark background.

\section{Public telephones}

Telephones to be used by the physically disabled should allow adequate space for wheelchairs to manoeuvre and facilitate ease of use.

The maximum height of all apparatus should be $1,400 \mathrm{~mm}$ from floor level.

Support rails, a flip down seat and shelf for bags should be incorporated in the design.

\section{Cash dispensers}

The route to a cash dispenser should always be accessible. Cash dispensers should be located at strategic locations so that they can be used by both visitors and employees. Lobbies are a good location provided there is sufficient space.

Cash dispensers should be within easy reach and mounted at a height not exceeding $1,400 \mathrm{~mm}$ from the floor and there should be a clear space in front of the dispenser being $1,500 \times 1,200 \mathrm{~mm}$.

\section{Alarms}

Audible alarms should incorporate simultaneous visual alarms for the hearing impaired.

Entry phones and intercom systems should incorporate a visual display to facilitate use by the hearing impaired.

Swipe card entry security systems should be designed to allow use by people with mobility disabilities.

\section{Exterior}

\section{Pedestrian accessibility}

Wide footpaths with slip-resistant surfaces, dropped curbs and no abrupt changes in level provide the means by which a disabled person is able to use the neighbourhood in which they shop. 
For blind people tactile cues at appropriate points to denote changes in level are important. Similarly footpaths must be free from protruding obstacles.

To determine whether a ramp is suitable, the following factors must be considered:

1. Can the ramp be designed so that it fits in with the shop?

2. Can the ramp be kept free of snow and ice?

3. Is there enough space to have a ramp with a slope that is not too steep?

4. Can the ramp give direct access to the main entrance?

The specific design of a ramp will depend on the particular characteristics of the site and building.

In general, handrails should be provided and the surface should be slip resistant. It should not be too long, too steep or have sharp corners.

Ramps must be at least $1,200 \mathrm{~mm}$ wide, and have a gradient of not more than 1:12. A level platform $1,500 \mathrm{~mm}$ long must be provided at the head of the ramp, and also at the foot of the ramp.

A $100 \mathrm{~mm}$ kerb is useful at the exposed edge of a ramp.

A nonslip finish must be provided to the ramp surface. Suitable treatments are:

1. In situ concrete with a ribbed surface finish and treated with carborundum.

2. Brick paving using a rough porous brick with flush joints.

3. Paving slabs with a nonslip finish.

4. Bitumen macadam with a $10 \mathrm{~mm}$ aggregate.

Ramp surfaces to be avoided are:

1. Granite rock and engineering bricks

2. Quarry tiles

3. Steel trowel finished concrete

4. Loose gravel

Ramps should, where possible, be kept away from the external walls of the buildings. Where it is necessary for a ramp to abut a building a vertical damp proof membrane must be provided between the ramp and the wall.

Care must be taken to ensure that a ramp against a building does not obstruct airbricks ventilating the under floor space.

The design considerations for exterior steps are similar to stairs, but the following factors should be taken into account, especially for people who are visually impaired:

1. Tactile and visual warnings should be installed as either ribbed or blister paving at the bottom and head of steps.

2. There should be a permanent contrast of colour finish at the nosing of each tread.

3. Handrails should have tactile cues at the top and bottom of a flight of stairs. 
Straight flights are easier to negotiate than dogleg or curved flights. Handrails are required no matter how short the flight. Steps should be well lit and shadows avoided.

\section{Vehicular accessibility}

Car parking close to the main entrance is important.

For shops with car parks, space especially reserved for a disabled person should be close to an accessible entrance.

Appropriate external signs such as the international symbols for access may be necessary indicating the way to specially designated parking areas.

The recommended standards for off-street car parking are:

1. At least one disabled space for every ten total spaces.

2. Off-street parking bays for wheelchair users must be at least 3,200 wide, preferably 3,700 wide.

3. Disabled spaces should be marked with a wheelchair symbol.

4. Disabled spaces should always be well lit and signed.

Where off-street parking is provided, remote from the shop, a route negotiable by wheelchair from the parking place to the main entrance should be provided.

\section{References}

Centre for Accessible Environments (2004a). A Guide to Designing Buildings, Which are Accessible to People with a Range of Disabilities, C.A.E., London.

Centre for Accessible Environments (2004b). Access Audits: A Guide and Checklists for Appraising the Accessibility of Public Buildings, C.A.E., London.

Disability Discrimination Act (1995) HMSO, London.

Disability Discrimination Act 1995 (2002). Code pf Practice: Rights of Access, Goods, Facilities, Services and Premises, HMSO, London.

Disability Rights Commission (2005). Making access to goods and services easier for disabled customers - A practical guide for small service providers www.drc.org.uk/the law/index.asp. Palfreyman, T. (1993). Designing for Accessibility: An Introductory Guide, C.A.E., London. Royal National Institute for the Blind (2004). Sign Design Guide, RNIB., London.

The Disability Discrimination (Providers of Services) (Adjustment of Premises) Regulations 2001 SI No. 3253.

\section{APPENDIX}

\section{SURVEY SHEET}

The following survey sheet will help in assessing the suitability of an existing building. By carefully using the survey sheet it should be possible to assess if an existing building is in need of adaptation and what refurbishment is required.

To assess the suitability of an existing building, each question in each section should be recorded for each room or facility in the building.

The number of 'Yes' and 'No' answers should be counted and put in the sub-total box. Where there are a high proportion of 'No' answers, appropriate refurbishment may be required. N/A answers count as equivalent to 'No'. Where the grand total shows a high proportion of 'No' answers, it may indicate the building is unsuitable and refurbishment is required. 


\section{Entrance}

Is there at least one primary entrance usable without assistance by someone in a wheelchair?

Is the main entrance accessible from the outside without having to use steps or stairs? Does the entrance door have a clear opening of at least $810 \mathrm{~mm}$ ?

Does the entrance have a vision panel $900-1,500 \mathrm{~mm}$ from finished floor level?

Is there a ramp outside the main entrance?

Are there handrails at the ramp at a height of $800-920 \mathrm{~mm}$ ?

Is there a level, paved area at least $1,500 \times 1,500 \mathrm{~mm}$ outside the door?

Is the threshold less than $15 \mathrm{~mm}$ high?

Is the accessible entrance identified by the international symbol of access?

Is there an automatic door-opening device?

Does the door have a clear opening of at least $810 \mathrm{~mm}$ ?

Are the door handles $760-915 \mathrm{~mm}$ from the floor?

Is there space to manoeuvre a wheelchair in the vestibule?

Are the floor surfaces slip resistance?

Are doors operable by a single effort? (Two leaf doors are not usable by disabled persons unless one of the two meets minimum clear opening requirement of $760-810 \mathrm{~mm}$ )

Do the door closers allow the use of the doors by disabled persons (delayed action)?

Are the lock and opening mechanisms operable with one hand?

Sub total

\section{Reception/foyer}

Does the door have a clear opening of at least $810 \mathrm{~mm}$ ?

Are the light switches within a range of $835-1,065 \mathrm{~mm}$ above the floor?

Is a $300 \mathrm{~mm}$ minimum unobstructed space provided next to the leading edge of all doors?

Is there adequate space to manoeuvre a wheelchair in the room?

Is the intercom within a range of $835-1,065 \mathrm{~mm}$ above the floor?

Is the window sill $760 \mathrm{~mm}$ or less from the floor?

Are the heating/air conditioning controls operable by a disabled person?

Are other electrical controls operable by a disabled person?

Is the counter height within a range of $835-915 \mathrm{~mm}$ ?

Are the floors slip resistance?

Does the carpeting allow the free movement of wheelchairs?

Are all surfaces free from glare?

Is the lighting adequate for visually impaired persons?

Is the signage appropriate for visually impaired persons (size, colour, contrast)?

Is there proper demarcation of differences in level by contrasting colour and appropriate lighting?

Is there an induction loop and/or other audio equipment installed for hearing impaired persons?

Sub total

\section{Sales floorloffice/workrooms}

Does the door have a clear opening of at least $810 \mathrm{~mm}$ ?

Are the door handles within a range of $750-915 \mathrm{~mm}$ above the floor?

Are controls operable by a disabled person?

Is the counter height within a range of $835-915 \mathrm{~mm}$ ?

Is there shelving that is reachable from a seated position?

Are the floors slip resistance?

Does the carpeting allow the free movement of wheelchairs?

Are all surfaces free from glare?

Is there adequate lighting for visually impaired persons?

Is there proper demarcation of differences in level by contrasting colour and appropriate lighting?

Does a blind person have an unobstructed path without protrusions from walls, floors or elsewhere?

Is the level of mechanical and other background noises low enough to avoid interference with sound reception on a conversational level by persons using hearing aids (less than $85 \mathrm{~dB}$ )?

Sub tota 


\section{Cafeteria and self-service dining area}

Does the door have a clear opening of at least $810 \mathrm{~mm}$ ?

Are the door handles within a range of $760-915 \mathrm{~mm}$ above the floor?

Are there accessible switches within a range of $835-1,065 \mathrm{~mm}$ above the floor?

Are the cooker controls accessible from a seated position?

Is the counter height $840 \mathrm{~mm}$ for use by a person in a wheelchair?

Is there knee space at the sink ( $\mathrm{min} .750$ wide $\times 250$ deep)?

Are the taps a lever type or other accessible type?

Are there any pullout storage units under the counter?

Is there toe space at the counter $230 \mathrm{~mm}$ high and $150 \mathrm{~mm}$ deep?

Is the wall mounted shelving reachable from a seated position (lower shelf not

higher than $1,250 \mathrm{~mm})$ ?

Does the carpeting allow the free movement of wheelchairs?

Are cutlery racks within reach of and visible to a wheelchair user?

Is the passage between chairs and tables at least $810 \mathrm{~mm}$ ?

Are some tables accessible for wheelchair users?

Is the self-service queuing corridor at least $856 \mathrm{~mm}$ wide?

Is there knee space under the tray slide at least $660 \mathrm{~mm}$ high?

Are all surfaces free from glare?

Is the lighting adequate for visually impaired persons?

\section{Sub total}

\section{Toilet/washroom}

Is the toilet/washroom designated for use generally accessible from other areas?

Is the designated toilet/washroom appropriately signposted?

Does the door have a clear opening of at least $810 \mathrm{~mm}$ ?

Are the door handles within a range of $760-915 \mathrm{~mm}$ above the floor?

Is there a turning circle $1,500 \mathrm{~mm}$ in diameter in the room?

Are there accessible light switches within a range of $835-1,065 \mathrm{~mm}$ above the floor?

Is the mirror and shelf less than $960 \mathrm{~mm}$ above the floor?

Are towel racks, soap holders and other fixtures in an accessible space, less than

$1,000 \mathrm{~mm}$ above the floor and less than $550 \mathrm{~mm}$ from the front of the counter?

Is the top of the toilet seat $475 \mathrm{~mm}$ above the floor?

Are there adequate plastic coated grab bars at the toilet?

Is there a space at least $600 \mathrm{~mm}$ wide beside the toilet to allow for a lateral transfer?

Is there space for a wheelchair at the front of the toilet (minimum depth $1,350 \mathrm{~mm}$ )?

If toilet is in a cubicle, is it at least $1,500 \mathrm{~mm}$ wide and $1,500 \mathrm{~mm}$ deep?

Are taps reachable and easily operable from a wheelchair?

Is the toilet-flushing device reachable and easily operated from a wheelchair?

Does the room have a device to signal for assistance?

Does the room have space for an attendant assisting someone in a wheelchair? Sub total

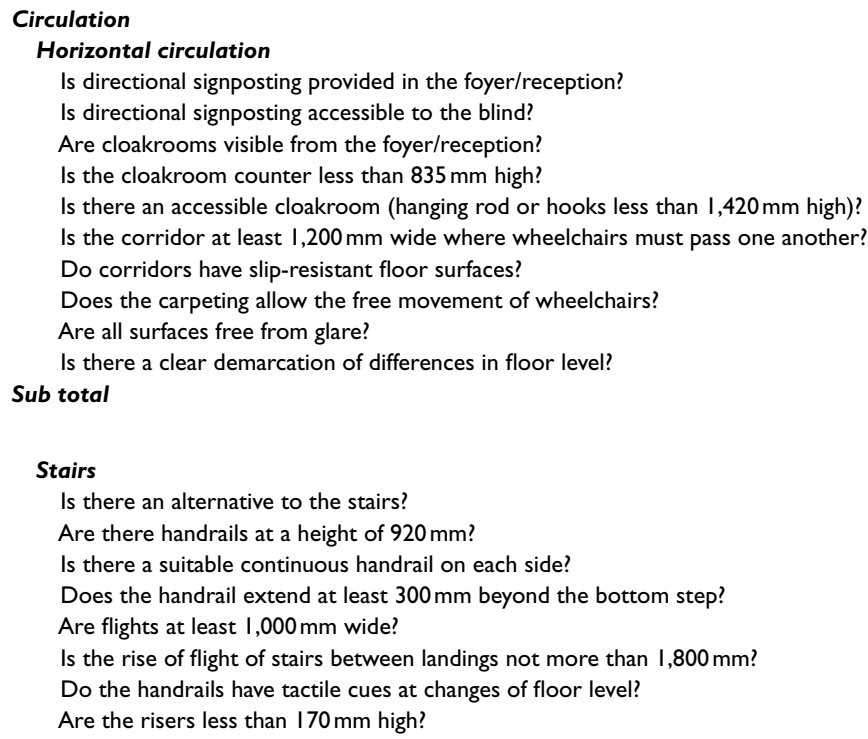


Are the treads more than $250 \mathrm{~mm}$ high?

Do the treads have a slip resistant finish or non-slip nosings?

Are the edges clearly marked for visually impaired people?

Have open risers been avoided?

Are the stairs well lit?

Sub total

Ramps

Are ramps provided where necessary?

Is the length between landings less than $9,000 \mathrm{~mm}$ ?

Is the ramp width at least $1,200 \mathrm{~mm}$ ?

Is the gradient $1: 12$ or less?

Is there a level landing at the top and bottom of the ramp at least $1,500 \mathrm{~mm}$

long and $1,200 \mathrm{~mm}$ wide or $1,500 \mathrm{~mm}$ wide if a door swings into it?

Is there a level landing at each change of direction?

Do both wheels of the wheelchair hit the slope or the landing at the same time?

Is there a suitable handrail on at least one side of the ramp $800 \mathrm{~mm}$ to $920 \mathrm{~mm}$

in height?

Does the handrail extend $300 \mathrm{~mm}$ beyond the top and bottom of the rail?

Does the handrail have tactile warning for blind users?

Are free-standing ramps at least $1,500 \mathrm{~mm}$ wide and their upturned edges $25-50 \mathrm{~mm}$

high for safety or protective bars no more than $200 \mathrm{~mm}$ above the ramp surface?

Is the ramp well lit?

Sub total

Lifts

Is there a lift that is accessible?

Is there a $1,500 \mathrm{~mm}$ turning circle in front of the lift?

Are the compartment dimensions sufficient to accommodate a wheelchair

(minimum $1,100 \times 1,400 \mathrm{~mm}$ )?

Does the compartment stop precisely at floor level or within $15 \mathrm{~mm}$ ?

Is the door opening at least $810 \mathrm{~mm}$ wide?

Are there tactile indications next to the call button indicating floor level?

Is the door equipped with an automatic safety reopening device?

Are the controls accessible from a wheelchair?

Are the controls accessible to the blind? (Raised symbols)

Are there audible signals for the blind? (With a dwell time of 5 seconds)

Is there emergency communication within reach?

Is there a handrail in the compartment?

Sub total

\section{Heating and ventilation}

Are draughts eliminated?

Is the humidity at the correct level?

Are all heating pipes and radiators enclosed?

Is the heating system easily operable?

Sub total

\section{Communal facilities}

Is there a telephone equipped for persons with hearing disabilities? Are switches and essential controls such as lights, fire alarms, and all similar controls within reach of a person in a wheelchair $(1,200 \mathrm{~mm}$ max height)? Are audible warning signals accompanied by simultaneous visual signals for persons with hearing or sight impairment?

Is there a directional signposting system for disabled people in the building?

Are exit signs easily visible to disabled persons?

Sub total

\section{Exterior}

Pedestrian accessibility

Are the footpaths at least $1,500 \mathrm{~mm}$ wide?

Does the footpath have dropped curbs?

Are the footpaths on a continuous run without steps or abrupt changes in level?

(Less than 1:20)

Are there tactile cues at the top and bottom of stairs, ramps, curbs?

Are the footpaths free from projecting obstacles (for blind users)?

Is the gradient of ramp less than $1: 12$ ? 
Is there a level landing at each change of direction of ramp?

Is the intersection of the ramp and the landing at a right angle to the direction of travel (ie both wheels hit landing at the same time)?

Is there a suitable handrail on at least one side of the ramp $800-920 \mathrm{~mm}$ in height?

Does the handrail extend $300 \mathrm{~mm}$ beyond the top and bottom of the ramp?

Does the handrail have tactile warning for blind users?

Are free standing ramps at least $1,500 \mathrm{~mm}$ wide?

Are there upturned edges $25-50 \mathrm{~mm}$ high for safety or protection bars no more

than $200 \mathrm{~mm}$ above the ramp surface?

Is the ramp protected from rain, snow and ice?

Is the building free from projecting external hazards?

Is appropriate tactile warning provided for people with impaired vision?

\section{Sub total}

\section{Vehicular accessibility}

Is there a parking space identified as reserved for vehicles for disabled persons

close to an accessible entrance?

Is there an international symbol of access indicating the direction to the

designated parking area?

Are there signs indicating the direction to the entrance for disabled persons?

Are there parking spaces $3.7 \mathrm{~m}$ wide for persons using wheelchairs, braces or

crutches?

Is the wheelchair transfer space on a level surface?

Does the designated parking space lead directly to an accessible entrance without crossing vehicular traffic?

Can a car be left in the designated parking area without having to be re-parked

by a driver after the disabled person is unloaded?

Is the parking area for disabled persons sheltered from rain, snow and ice?

Is the taxi or car drop-off sheltered?

Sub total

\section{Summary sheet totals}

Entrance

Foyer/reception

Sales floor/office/workrooms

Cafeteria/dining area

Toilet/washroom

Horizontal circulation

Stairs

Ramps

Lifts

Heating and ventilation

Communal facilities

Pedestrian accessibility

Vehicular accessibility 